\title{
Multiple Chromosome Polymorphism in Gobius paganellus (Teleostei, Perciformes)
}

\author{
Guillermo Thode, Vicente Giles and \\ M. Carmen Alvarez
}

\begin{abstract}
Departamento de Genética, Facultad de Ciencias, Universidad de Málaga, Malaga, Spain.
\end{abstract}

Chromosome preparations from 46 specimens of $G$. paganellus were studied, revealing seven different karyomorphs: $D_{2}$ $(2 n=46, N F=46), D_{1}(2 n=47, N F=47), B(2 n=48, N F=48), F_{1}(2 n=47, N F=48), F_{2}(2 n=46, N F=48), D_{1} F_{1}$ $(2 n=46, N F=47), I_{1}(2 n=48, N F=49)$. It is proposed that the mechanisms involved are deletions, fusions and inversions. The meiotic results suggest that the same chromosome pair was engaged in both the fusion and the deletion rearrangements. Intra-individual polymorphism was found in only one specimen. This and the range of karyomorphs suggest that this variation is regularly inherited.

\section{INTRODUCTION}

Unlike most other animals, chromosomal polymorphism has been detected in relatively few species of fishes and these are mainly Salmonids. They show both inter and intra-individual variation most commonly taking the form of Robertsonian translocations (Thorgaard, 1976; Hartley and Horne, 1982).

The family Gobiidae comprises a very large group of fishes of which only about 65 species have been karyotypically analysed. These show a large range in both their chromosomal number and morphology which clearly signifies the important role played by the chromosomal rearrangements in their phylogeny. The systematics of this group, based on conventional criteria, has been rather debatable and has given rise to a prolific synonymy especially noticeable in G. paganellus (Hureau and Monod, 1973). Moreover chromosome numbers given by other authors for this species (Cataudella et al., 1973; Colombera and Rasotto, 1982) disagree with that previously reported by us (Thode et al., 1983). These discrepancies have led us to undertake an extensive study in order to clarify the situation in this species. The first sample analysed has shown a multiple chromosome polymorphism consisting of seven karyomorphs which could in some respects account for the intraspecific variability in the morphological traits.

\section{MATERIAL AND METHODS}

46 specimens of both sexes of $G$. paganellus from a single population were collected in the south Mediterranean coast during 1982 and 1983.

Conventional mitotic and meiotic analyses were carried out on cells from spleen, kidney and testis using the technique of Capanna et al. (1972), slightly modified by Alvarez et al. (1980). For ordering the karyotypes the chromosomes were classified according to the criteria of Levan et al., (1964).

\section{RESULTS}

Examination of a minimum of 35 metaphases per specimen revealed 7 distinct groups of individuals with different chromosome complements (detail in table 1 and fig. 1). These karyomorphs are distinguished by chromosome number and by Fundamental Number and are designated according to the chromosomal rearrangements apparently involved in its genesis. It is worth pointing out that, in all the described morphs and in the metaphases with the most stretched chromosomes, two big pairs and one small pair of subtelocentrics (arrowheads fig. 1) could be identified, the last pair being recognized as the carrier of the NORs (Thode and Alvarez, 1983a). The variable appear- 
Table 1 Karyological data of 46 specimens of $G$. paganellus showing 7 karyomorphs

\begin{tabular}{|c|c|c|c|c|c|c|c|}
\hline \multirow[b]{2}{*}{ Morphs } & \multirow[b]{2}{*}{ No. individuals } & \multicolumn{2}{|c|}{ No. of metaphases } & \multirow[b]{2}{*}{$2 n$} & \multicolumn{3}{|c|}{$\begin{array}{l}\text { Karyotype characteristics } \\
\text { morphology }\end{array}$} \\
\hline & & Somatic & Meiotic & & M-Sm & St-A & NF \\
\hline $\mathrm{D}_{2}$ & $4 \delta^{\circ}$ & 194 & 62 & 46 & - & 46 & 46 \\
\hline $\mathrm{D}_{1}$ & 38 & 285 & 73 & 47 & - & 47 & 47 \\
\hline & $\left\{5 \delta^{\circ}\right.$ & 153 & 56 & 48 & - & 48 & 48 \\
\hline B & $\left\{\begin{array}{l}19 \\
19\end{array}\right.$ & 75 & - & 48 & - & 48 & 48 \\
\hline & $\left\{20^{\circ}\right.$ & 123 & - & 47 & 1 & 46 & 48 \\
\hline $\mathrm{F}_{1}$ & $2 q$ & 110 & - & 47 & 1 & 46 & 48 \\
\hline & $\int 50^{\circ}$ & 276 & 80 & 46 & 2 & 44 & 48 \\
\hline $\mathrm{F}_{2}$ & $\{159$ & 735 & - & 46 & 2 & 44 & 48 \\
\hline $\mathrm{D}_{1} \mathrm{~F}_{1}$ & $80^{\circ}$ & 358 & 52 & 46 & 1 & 45 & 47 \\
\hline $\mathrm{I}_{1}$ & $10^{\circ}$ & 96 & - & 48 & 1 & 47 & 49 \\
\hline
\end{tabular}

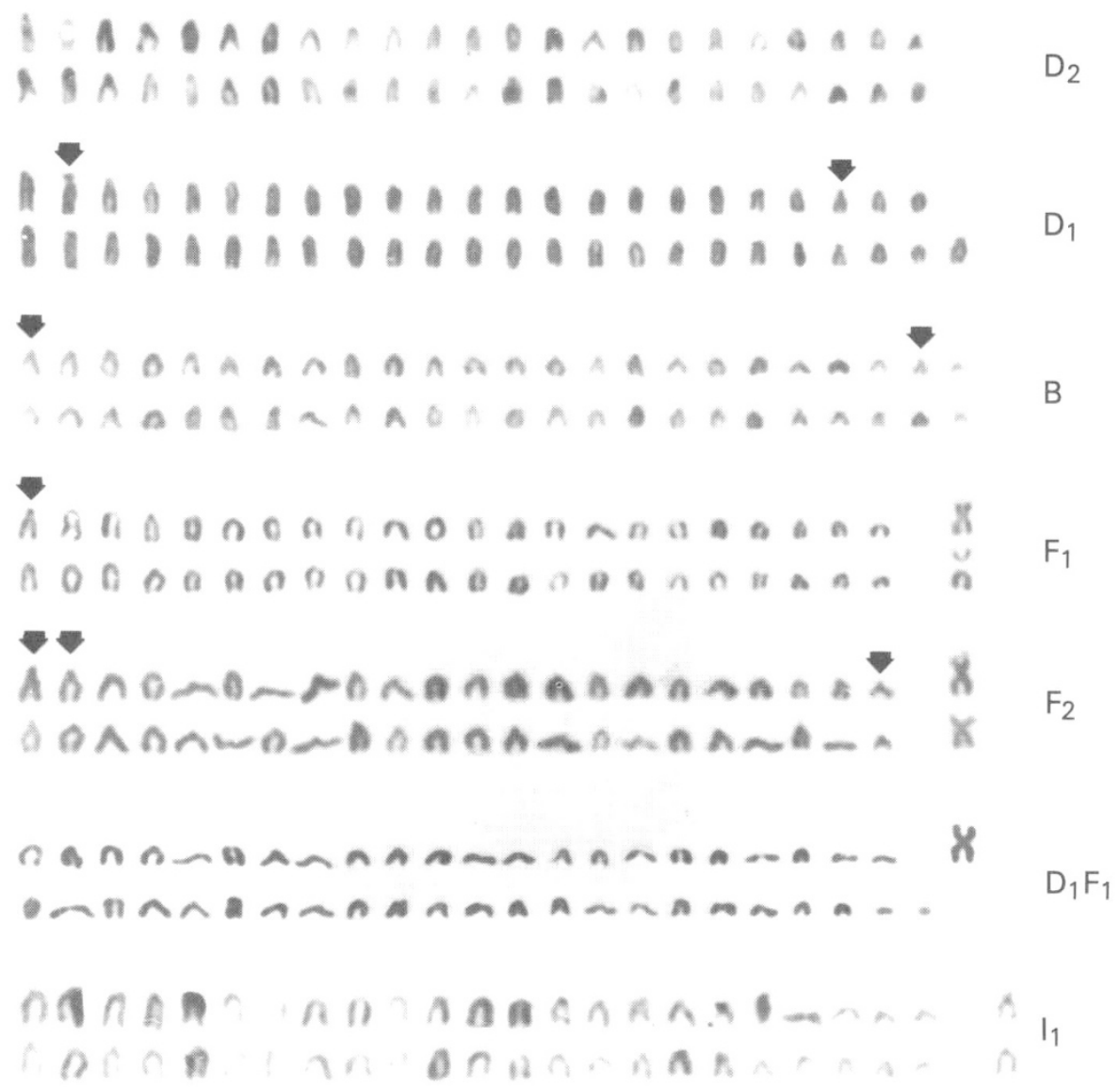

Figure 1 Karyotypes from seven different morphs of $G$. paganellus: $\mathrm{D}_{2}(2 n=46, N F=46), \mathrm{D}_{1}(2 n=47, N F=47)$, B $(2 n=48, N F=48), \mathrm{F}_{1}(2 n=47, N F=48), \mathrm{F}_{2}(2 n=46$,

ance of these small arms was interpreted as a consequence of the degree of the chromosome condensation which would condition their staining properties.
$N F=48), \mathrm{D}_{1} \mathrm{~F}_{1}(2 n=46, N F=47), \mathrm{I}_{1}(2 n=48, N F=49)$. The variable subtelocentric chromosomes are indicated by arrowheads.

Intra-individual polymorphism was only found in a single specimen which showed 86 metaphases as the $F_{1}$ morph, 11 metaphases as the $B$ morph, and 12 metaphases as the $F_{2}$ morph. 
The analyses of the meiotic metaphase-I in some of the karyomorphs (fig. 2) allowed us to confirm their respective diploid numbers, as well as the unpaired acrocentric chromosome of the $D_{1}$ morph (arrowhead), the heterologous bivalent in the $\mathrm{D}_{1} \mathrm{~F}_{1}$ morph (arrowhead), and the ring configuration of the metacentric pair of the $F_{2}$ morph (arrowhead).

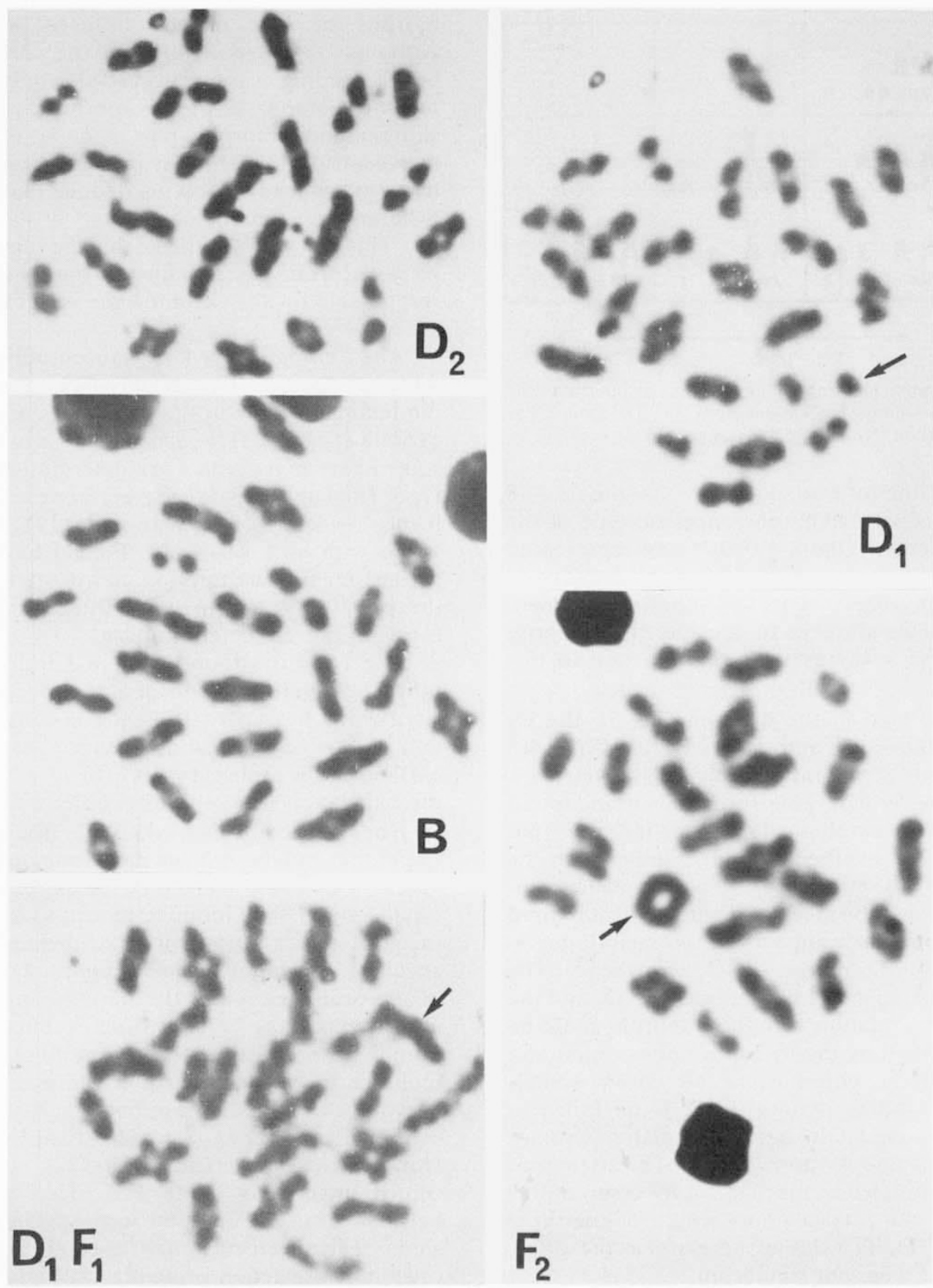

Figure 2 Meiotic metaphases-I in some morphs of $G$. paganellus (see in the text the significance of the arrowheads). 


\section{DISCUSSION}

The differences in the chromosome complements among the individuals under study reveal clearly an inter-individual polymorphism in which different chromosomal changes are involved (fig. 3).

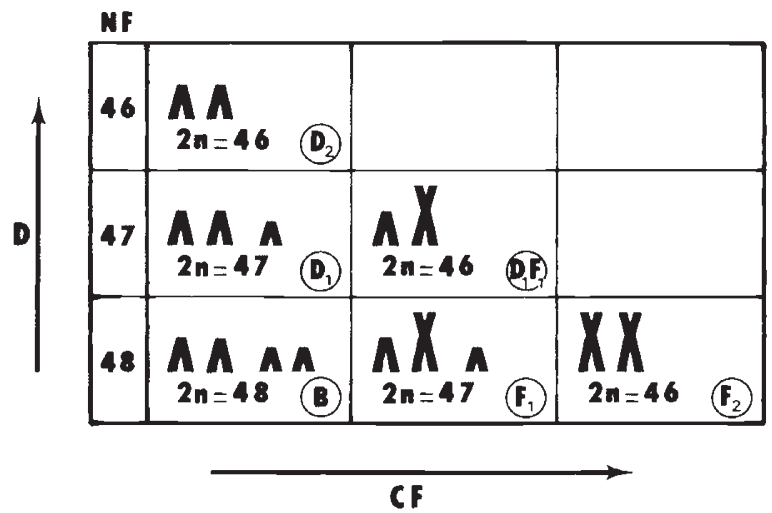

Figure 3 Diagram showing the mechanisms giving rise to the differences among six karyomorphs. $D=$ = Deletion, $C F=$ centric fusion, $\mathrm{NF}=$ Fundamental Number.

Several lines of evidence argue that the $2 n=48$ karyotype is most likely the ancestral type of the modern teleosts (Ohno, 1974), being represented also in some species of the family Gobiidae (Thode and Alvarez, 1983b). This and other complementary arguments allow us to consider the $\mathrm{B}$ morph $(2 n=48, N F=48)$ as the primitive one in this species.

As illustrated in the diagram (fig. 3), the $D_{1}$ $(2 n=47, N F=47)$ and $\mathrm{D}_{2}(2 n=46, N F=46)$ morphs could represent respectively the heterozygote and the homozygote forms of an aneuploid karyotype. The cytological evidence indicates that this decrease in the diploid number can be explained by the meiotic loss of one small acrocentric which would be the homologue of the unpaired chromosome which appears in the meiotic metaphase I of the $D_{1}$ morph (fig. 2, arrowhead). The apparently similar viability of both the $D_{1}$ and the $\mathrm{D}_{2}$ morphs in relation with the $\mathrm{B}$ morph, could be readily justified by the loss of a not essential and heterochromatic chromosome (B chromosome), but the $\mathrm{C}$ banding pattern in the latter failed to show any completely heterochromatic chromosome (Thode and Alvarez, 1983a). The attempt to establish the deletion mechanism by comparative analyses of the total genome length of the three morphs $\left(B_{1}, D_{1}, D_{2}\right)$ was unsuccessful as the differences found were not significant.

The $F_{1}(2 n=47, N F=48)$ and $F_{2}(2 n=46$, $N F=48)$ morphs are most probably the result of a Robertsonian polymorphism involving the fusion of two acrocentric chromosomes, giving rise to a metacentric in heterozygosity and homozygosity respectively (fig. 3 ).

The origin of the $\mathrm{D}_{1} \mathrm{~F}_{1}$ morph $(2 n=46, N F=$ 47) could be apparently explained as the result of hybridisation between $D_{1}$ or $D_{2}$ with the $F_{1}$ or $F_{2}$ morphs or loss of the unfused ${ }^{\top}$ homologue. Although the identification of the chromosomes by $G$ banding was unsuccessful, analysis of the meiotic metaphases of this morph (fig. 2) which shows a heteromorphic pair made up of the fused metacentric and one of the medium sized acrocentrics (arrowhead), allow us deduce that the latter is homologous to one of the arms of the metacentric. This fact would indicate that the same chromosome pair is involved in the two main mechanisms responsible for the chromosome variability in this species.

The finding of the $D_{1} F_{1}$ morph only in males, added to the detection of only $F_{2}$ karyomorphs in the females, led us in the first stages of this study (Thode et al., 1983) to associate these two chromosome alternatives with a sex determinism XX-XY type. The subsequent discovery of new karyotypic forms, associated only with males $\left(D_{1}, D_{2}, D_{1} F_{1}\right.$, $\left.I_{1}\right)$ or with both sexes $\left(B_{1}, F_{1}, F_{2}\right)$ has led us to review our first assumption and to study in depth the possible involvement of these chromosomal forms in the sex determination.

The $I_{1}$ morph found only in 1 individual signifies the heterozygote form of a pericentric inversion which has arisen from the B morph (fig. 3), and is a reflection of a new rearrangement in the chromosomes of this species. The identification of the pair involved was not possible.

The mechanisms involved in the interindividual polymorphism in G. paganellus correspond with those concerned in the chromosome phylogeny of the Gobiidae group, as can be seen in fig. 4 where karyotypic data belonging to 65 species of this family have been plotted on a system of co-ordinates with the diploid numbers as abscissae and the FN as ordinates. The size of the points are proportional to the number of species included in each. The arrowed lines indicate the karyotype trends, shown as being derived from the primitive karyotype ( 48 acrocentrics) by deletions (Line I), by centric fusion (Line II), and by pericentric inversions (Line III). This parallelism between intra-specific and inter-specific chromosomal rearrangements might account for the karyotype orthoselection principle of White (1973).

The proportions of the three possible classes of fish arising from the two main proposed 


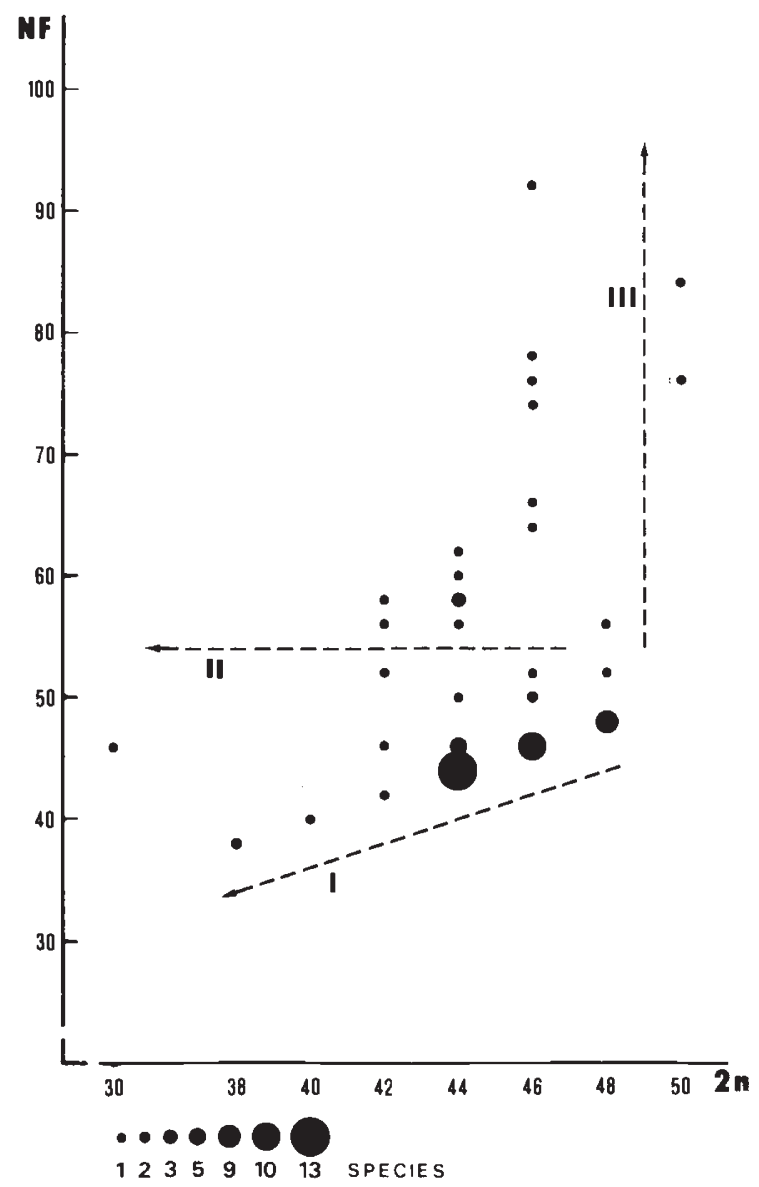

Figure 4 Diagram showing the dominant karycevolutive trends (arrow-headed lines) in 65 species of Gobies. a) decrease in both $N F$ and $2 n$ by deletions-Line $I$; b) decrease in $2 n$ by centric fusion-Line II; c) increase in $N F$ by pericentric inversions-Line III.

mechanisms were respectively: 6 (homozygous), 11 (heterozygous), 4 (homozygous) for the deletion, and 6 (homozygous), 12 (heterozygous) and 20 (homozygous) for the fusion. The observations for the former fit the Hardy-Weinberg expectations $\left(\chi^{2}=0 \cdot 209, P \simeq 0 \cdot 90\right)$ predicted for an inherited polymorphism. In contrast, the frequencies observed for the fusion mechanism differ significantly $\chi^{2}=0.08, P \simeq 0.01$ from those expected for the Hardy-Weinberg equilibrium. In both cases the samples are rather small for statistically reliable results so more extensive analyses are needed. In any case the low proportion of intra-individual polymorphism (about 2 per cent) found by us would suggest, not a somatic origin of the interindividual differences, but an inherited one.
Nevertheless the intra-individual variations found in one individual could be the result of somatic segregation (Beçak et al., 1966) superimposed on inherited differences.

Acknowledgment The authors are grateful to Dr D. Annan (The Hannah Research Institute, Ayr, Scotland) for reviewing the manuscript and E. García for technical assistance.

\section{REFERENCES}

Alvarez, M. C., CANO, J. AND THODE, G. 1980. DNA content and chromosome complement of Chromis chromis (Pommacentridae, Perciformes). Caryologia, 33, 267-274.

BEÇAK, W., BEÇAK, M. C. AND OHNO, S. 1966. Intraindividual chromosomal polymorphism in the green sunfish (Lepomis cyanellus) as evidence of somatic segregation. Cytogenetics, $5,313-320$.

CAPANNA, E., CATAUDELla, S. AND VOLPE, R. 1972. Osservazioni morfologiche e cariologiche su di un ibrido Salmo trutta $\times$ Salvelinus fontinalis. Boll. Pesca Pisci Idrobiol., 27, 245-257.

CATAudella, S., CiVitelli, M. V. AND CAPANNA, E. 1973. The chromosomes of some Mediterranean teleosts: Scorpaenidae, Serranidae, Labridae, Blennidae, Gobiidae (Pisces: Scorpaeniformes, Perciformes). Boll. Zool. Roma, 40, 380-385.

COLOMBERA, D. AND RASOTTO, M. 1982. Chromosome studies in male of Gobius niger jozo ( $\mathrm{Padoa}$ ) and Gobius paganellus (Linneo) (Gobiidae, Osteichthyes). Caryologia, 35, 257 260.

HARTLEY, S. E. AND HORNE, M. T. 1982. Chromosome polymorphism in the rainbow trout (Salmo gairdneri Richardson). Chromosoma, 87, 461-468.

HUREAU, J. C. AND MONOD, T. 1973. Check-list of the fishes of the North-eastern Atlantic and of the Mediterranean (Clofnam I and II). UNESCO. P.U.F. Paris 683, 331 pp.

LEVAN, A., FREDGA, K. AND SANDBERG, A. A. 1964. Nomenclature for centromeric position on chromosomes. Hereditas, 52, 201.

OHNO, S. 1974. Animal Cytogenetics Vol. 4. Chordata I: Protochordata, Cyclostomata, and Pisces. Gebruder Borntraeger, Berlin, Stuttgart. 99 pp.

THODE, G. AND ALVAREZ, M. C. $1983 a$. Comparative analysis of nucleolus organizer regions in six species of Gobius. Abstracts of The 8th International Chromosome Confer ence, Lübeck. 6-1.

THODE, G. AND ALVAREZ, M. C. $1983 b$. The chromosome complements of two species of Gobius (Teleostei, Perciformes). Experientia, 39, 1312-1314.

THODE, G., CANO, J. AND ALVAREZ, M. C. 1983. A karyological study on four species of Mediterranean Gobiid fishes Cytologia 48, 131-138.

THORGAARD, G. H. 1976. Robertsonian polymorphism and constitutive heterochromatin distribution in chromosomes of the rainbow trout (Salmo gairdneri). Cytogenet. Cell Genet, 17, 174-184.

WHITE, M. J. D. 1973. Animal Cytology and Evolution. Cambridge Univ. Press. 3rd ed., 961 pp. 